\title{
Capsule Commentary on Homoya et al., Uncertainty as a Key Influence in the Decision to Admit Patients with Transient Ischemic Attack
}

\author{
F. Amos Bailey, MD \\ J Gen Intern Med 34(9): 1849 \\ DOI: $10.1007 / \mathrm{s} 11606-018-4802-2$ \\ () Society of General Internal Medicine 2019
}

University of Colorado Anschutz Medical Campus, Aurora, CO, USA.

I $\mathrm{n}$ this study, Homoya and colleagues explore the real-world management of patients with TIAs in 14 VA Medical Centers from around the country. A TIA is an example of an infrequent but high-risk event that non-specialists need to recognize and appropriately manage. ${ }^{1}$ What happens in the first few days after having a TIA is critical since the risk of a potentially disabling stroke is greater than $10 \%$ and the risk of death is $2.6 \%$ at 90 days. $^{2}$

The authors demonstrate that TIA management is suboptimal for many patients and that providers have an incorrect estimation regarding management of TIA patients by their facility, believing that almost all TIA patients were admitted to inpatient setting for workup, management of risk factors, and treatment when in fact many patients are not admitted. This is illustrated in the qualitative section in which a staff member said "Most probably do get admitted" (meaning people with a TIA) when in fact more than a third of patients at that facility with TIA were discharged from the ED.

The underlying theme in this study is uncertainty. Providers are uncertain of what to do because they lack guidance from their facility, they are uncertain of the appropriate evaluation and management of this infrequent but high-risk event in which the patient looks and feels well, and there is pressure to reduce "unnecessary" hospital admissions. Clear guidelines could be helpful; implementation science and quality improvement interventions could reduce uncertainty by testing "TIA protocols" to address key element of the admission decision-

making process and to standardize both evaluation of TIA and delivery of secondary prevention strategies. ${ }^{3,4}$

Corresponding Author: F. Amos Bailey, MD; University of Colorado Anschutz Medical Campus, Aurora, CO, USA (e-mail: amos. bailey@ucanschutz.edu).

\section{Compliance with Ethical Standards:}

Conflict of Interest: The author declares that he does not have a conflict of interest.

\section{REFERENCES}

1. Homoya BJ, Damush TM, Sico JJ, Miech EJ, Arling GW, Myers LJ, Ferguson JB, Phipps MS, Cheng EM, Bravata DM. Uncertainty as a Key Influence in the Decision to Admit Patients with Transient Ischemic Attack. J Gen Intern Med. https://doi.org/10.1007/s11606-018-4735-9

2. Johnston SC, Gress DR, Browner WS, Sidney S. Short-term prognosis after emergency department diagnosis of TIA. Jama. 2000;284(22):2901-6. Epub 2001/01/09.

3. Johnston SC, Albers GW, Gorelick PB, Cumbler E, Klingman J, Ross MA, Briggs M, Carlton J, Sloan EP, Vaince U. National Stroke Association recommendations for systems of care for transient ischemic attack. Annals of neurology. 2011;69(5):872-7. Epub 2011/03/11. https://doi.org/10. 1002/ana.22332.

4. Easton JD, Saver JL, Albers GW, Alberts MJ, Chaturvedi S, Feldmann E, Hatsukami TS, Higashida RT, Johnston SC, Kidwell CS, Lutsep HL, Miller E, Sacco RL. Definition and evaluation of transient ischemic attack: a scientific statement for healthcare professionals from the American Heart Association/American Stroke Association Stroke Council; Council on Cardiovascular Surgery and Anesthesia; Council on Cardiovascular Radiology and Intervention; Council on Cardiovascular Nursing; and the Interdisciplinary Council on Peripheral Vascular Disease. The American Academy of Neurology affirms the value of this statement as an educational tool for neurologists. Stroke 2009;40(6):2276-93. Epub 2009/05/ 09. https://doi.org/10.1161/strokeaha.108.192218.

Publisher's Note Springer Nature remains neutral with regard to jurisdictional claims in published maps and institutional affiliations.

Published online July 8, 2019 